\title{
A TRADUÇÃO DE TEXTOS PARA AS LÍNGUAS EXÓTICAS NOS SÉCULOS XVI E XVII - NATUREZA E CARACTERÍSTICAS
}

\author{
Eduardo de Almeida Navarro*
}

RESUMO: A tradução de textos para as línguas americanas, africanas e asiáticas feita pelos europeus que, nos séculos XVI e XVII iniciavam a conquista ultramarina, teve o propósito fundamental de converter as populações de além-mar para o Cristianismo. Esses textos destinavam-se, alguns, às populações autóctones e, outros, aos próprios missionários e tiveram maior variedade nas regiões habitadas por sociedades de tradição escrita. No caso das gramáticas, o que se nota é a forte intertextualidade com o modelo latino. Neste artigo, mostramos quais foram os textos que a expansão européia buscou traduzir para as linguas ditas "exóticas" naqueles dois séculos.

Palavras-chave: línguas exóticas, tradução, missionários.

\section{INTRODUÇÃO}

O termo "exótico" tem, aqui, acepção nitidamente eurocêntrica. Segundo Morais Silva, em seu "Grande Dicionário da Língua Portuguesa" (Vol. IV, p. 1013-1014), “diz-se ordinariamente do que é extra-europeu e, mais especialmente, das terras longinquas tropicais". O termo é empregado, hodiernamente, mais em seu sentido figurado "de estranho, es-

(*) Professor do Departamento de Letras Clássicas e Vernáculas da FFLCH-USP. 
quisito, estapafúrdio". Vem do latim "exoticus" e esse do grego

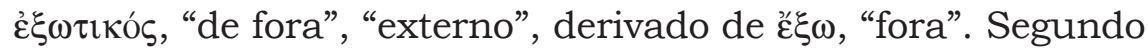
Corominas (1954, p. 464 ), o termo está documentado na língua espanhola desde 1614. No francês, contudo, o termo foi usado por Rabelais em Pantagruel, IV, 1, já no século XVI:

"Marchandises exoticques et peregrines, qui estoyent par les halles du port."

(apud Littré, Dictionnaire de la Langue Française, vol. II, p. 1566)

O caráter eurocêntrico do termo merece algumas reflexões. Com efeito, foi na Europa que se gestaram as novas condições econômicas, políticas, sociais e culturais que dariam ao mundo hodierno seus contornos definidores. Foi da Europa que partiram os impulsos transformadores que, progressivamente, iriam mundializar a economia capitalista, modelando o mundo imagine et similitudine sua, homogeneizando espaços e culturas, europeizando o orbe terrestre.

Ponto fulcral da nova situação geopolitica que se configurava desde o final do século quinze, a questão lingüística iria, naquele momento, emergir de modo espetacular.

Com as Grandes Navegações, nos séculos XV e XVI, a Europa iria defrontar-se com uma gama variadíssima de línguas, não somente asiáticas mas também africanas e americanas, o que esboroava a vetusta concepção da universalidade do árabe no mundo d'além mar.

O afluxo de termos de diferentes linguas americanas, africanas e asiáticas para línguas européias, desde o século XVI, firmou, assim, o conceito de exotismo, que passou à posteridade e chegou até nós. Se o árabe estivera próximo demais para ser qualificado de língua exótica, o mesmo não ocorreria, dessa feita, com o maia, o quêchua, o tupi, o guarani, o quimbundo, o guineense, o canarim, o malabar, o sânscrito, o chinês, o japonês, o tailandês, etc., cujo conhecimento tor- 
nava-se indispensável para o bom sucesso da empresa colonial. Refere Azurara (apud Fonseca, 1940, p.158), que o Infante D. Henrique, em 1436, ao se iniciarem as Grandes Navegações, incitara um marinheiro, Gonçalves Baldaia, a prosseguir na exploração das novas terras descobertas e recomendou-lhe:

"Trabalhai por haver a língua dessa gente."

Se a língua era a companheira do Império, consoante Nebrija, se as línguas latina, grega e hebraica, ("as princesas do mundo", na expressão de João de Barros) passam, agora, segundo Kukenheim (1932), a ceder lugar à tríade românica (o italiano, o francês e o castelhano), não é menos certo que, sem o domínio das línguas exóticas recém-conhecidas, a dominação européia sobre as novas terras descobertas quedaria extremamente dificultada ou até mesmo obstaculizada.

Se tal era verdade no que tange à esfera politica da colonização, o mesmo se diga em relação à expansão do Catolicismo, a qual, além de sentido religioso, adquiria dimensão política, haja vista que o imperialismo quinhentista europeu era considerado um ato de "acrescentamento da fé". Com efeito, somente o conhecimento das linguas das novas terras descobertas facultaria a ação missionária. Bem o vislumbrou Inácio de Loyola, que, nas Constituições de 1540, escrevia:

\footnotetext{
"Ad maiorem unionem eorum qui in Societate vivunt \& c. singuli addiscant eius regionis linguam, in qua resident."

"Para a maior união daqueles que na Sociedade vivem e doutros, cada um aprenda a língua da região em que reside."

(apud Araújo, 1952, Prólogo)
}

Se o conhecimento e o uso das línguas exóticas faziamse necessários para a expansão política e econômica européias, permitindo a adaptação a realidades naturais totalmente 
diversas, facultando o entendimento com potentados locais, dos quais dependia o bom sucesso da estratégia colonizadora (lembre-se do que significou o apoio dos morubixabas indigenas para a expulsão dos franceses do Brasil por Mem de Sá), a produção de textos escritos era necessária para que a catequese pudesse vingar. Efetivamente, urgia traduzirem-se catecismos para as línguas exóticas e dotar os missionários de um domínio lingüístico suficiente para pregar, ouvir confissões, enfim, desempenhar seu múnus apostólico. No prólogo de sua Arte de la lengua quichua, o Pe. Diego de Torres Rubio (1619) expunha tal triplice desiderato:

"Con los preceptos y reglas generales que van en este Arte de la lengua Quichua, puede uno aprender a hablar congruamente lo suficiente y necesario que es menester para catequizar, confesar y predicar."

Desse modo, fazia-se imperiosa a necessidade de se gramaticalizarem as linguas exóticas e de se traduzirem textos para elas e tal foi a tarefa assumida pelas grandes ordens religiosas: os franciscanos, os dominicanos, os agostinianos e os jesuitas, que dotaram muitas daquelas línguas de uma literatura escrita, fato antes desconhecido por muitas sociedades, que eram ágrafas.

\section{A tradução de teXtos Para as línguas exóticas}

A comunicação entre o mundo europeu e o mundo exótico apresentava dois niveis principais: o puramente dialógico e o nível pedagógico. No nível dialógico, situa-se o mercantilismo, que necessitava estabelecer bases comerciais em ultramar, devendo, assim, contar com a colaboração de algumas camadas sociais das regiões dominadas. O segundo nivel de comunicação com o mundo exótico, que era o pedagógico, foi aquele em que se deu o trabalho apostólico, missionário: 
não se tratava mais de dialogar, mas, agora, de ensinar, na sua acepção etimológica, isto é, "imprimir signos" (do latim in + signare). O europeu passará, então, a produzir literatura nas línguas exóticas, destinada aos povos d'além-mar, enquanto puramente ouvintes ou enquanto leitores dos textos produzidos. No caso da produção de textos para serem lidos pelos povos de ultramar, eles deveriam, no que tange às sociedades letradas, ser vertidos para as suas línguas ou no seu próprio sistema gráfico ou no alfabeto latino (dando-se, então, a transliteração). Neste último caso, impunha-se a alfabetização dos povos exóticos no sistema gráfico latino. $\mathrm{Na}$ hipótese de haver a produção de textos destinados a sociedades ágrafas, somente a alfabetização far-se-ia necessária.

$\mathrm{Na}$ América, muitas linguas indígenas tornar-se-iam as linguas mais usadas por quase todos os membros do sistema colonial. Milhares de crianças cresceriam em ambientes bilíngües. Desse modo, publicar textos em línguas indígenas passava a fazer sentido em dois aspectos: para dotar os índios ou colonos alfabetizados de textos que eles pudessem ler (em línguas que eram bem mais faladas que o castelhano e o português) ou oferecer aos missionários aquilo que esses deveriam ler para instruir os índios ou os colonos bilíngües. Nesta última categoria estavam as gramáticas, os sermonários, os confessionários, os textos homiléticos, etc. Na categoria anterior estavam as cartilhas, os catecismos, as biografias de santos, etc.

\subsection{As CARTILHAS EM LÍNGUAS EXÓTICAS}

Fato de subida importância foi a existência de cartilhas em linguas exóticas, provando que houve alfabetização nelas já nas primeiras décadas do século XVI. Temos notícia da Cartilla para los niños, en lengua tarasca, pelo Frei Maturino Gilberti, impressa no México no ano de 1559. Ela foi reimpressa em 1575 (apud Viñaza, 1892, p.30). Viñaza dá-nos 
notícia, também, de uma cartilha em língua chuchona, vinda ao prelo no ano de 1580. Seu título é: Cartilla y Doctrina Christiana, breve y compendiosa, para ensenar los niños: y ciertas preguntas tocantes a la dicha Doctrina, por manera de Dialogo: traduzida, compuesta, ordenada y romançada en la lengua Chuchona del pueblo de Tepexic de la Seda. Seu autor era o dominicano Frei Bartholomé Roldan e foi impressa no México.

Sabemos também, por Viñaza (op. cit., p. 115), da existência de uma Cartilla mayor en lengua Castellana, Latina y Mexicana, publicada no México em 1683.

Em 1554, sob os auspícios de D.João III, inicia-se a publicação de obras didáticas destinadas não só ao ensino de português aos povos de ultramar, mas à alfabetização desses nas próprias línguas exóticas. É a primeira vez que se imprime numa língua asiática dentro da Europa e por iniciativa de europeus. Naquele ano, assim, veio ao prelo a Cartilha que contem brevemente ho q todo christão deve aprẽder pera sua salvação. A qual el rey dom Johão terceiro desse nome nosso Senhor mandou ẽ lingoa Tamul e Português cõ a declaraçam por cima de vermelho. Os autores da cartilha são três indianos bilingües: Vicente de Nazareth, Jorge de Carvalho e Tomé da Cruz. A lingua tamul ou malabar é a mais falada das línguas dravídicas da Índia e possui rica literatura.

A Cartilha...em Tamul e Português trazia uma grande inovação pedagógica, utilizando duas técnicas concomitantes: a interlinearidade e o exercício estrutural. O Credo católico vinha, nela, assim:

$\begin{array}{llll}\begin{array}{l}\text { Dos ceos } \\ \text { Agájamũm } \\ \text { Creo em }\end{array} & \begin{array}{l}\text { e da terra } \\ \text { bũmium } \\ \text { Deos }\end{array} & \begin{array}{l}\text { criador } \\ \text { paracheuãn }\end{array} & \begin{array}{l}\text { todo } \\ \text { çaravamũn } \\ \text { padre todo poderoso }\end{array} \\ \begin{array}{lll}\text { poderoso } & \text { padre } & \text { em Deos }\end{array} & \text { creo. } \\ \begin{array}{l}\text { ánauanè: pidane tambirane vizvácam. } \\ \text { criador dos ceos e da terra. }\end{array} & \end{array}$

(Apud Pinto, 1948) 
A interlineação é apresentada, assim, em tríplice registro: na linha do meio está escrita a frase em tamul, na linha de baixo vem a tradução portuguesa e na linha de cima (a primeira de cada série), que no original aparece em letras vermelhas, vem uma versão portuguesa segundo a ordem sintagmática própria do tamul. Outro exemplo:

- Ni naçaranió? A tradução indicada na Cartilha é "Vós sois cristãos?", mas a "declaração", isto é, a tradução segundo a ordem sintagmática do tamul é "Vós cristãos sois?"

Segundo Lebon, em sua Psychologie de l'Education (apud Pinto, 1948, p.358), esse é "o sistema mais profícuo para o conhecimento de uma língua diferente, sem necessidade de gramática nem de dicionário". Consoante Buescu (1983, p. 62), "do ponto de vista pedagógico, parece-nos poder identificar o método de ensino seguido como singularmente próximo do ensino estrutural moderno (...). A aprendizagem é feita não em nivel de quadros gramaticais nem em nível de vocabulário amorfo, mas em nivel de estruturas sintáticas".

Se as cartinhas de João de Barros e de outros autores, como D. Diogo de Ortiz Vilhegas destinavam-se a ensinar português às crianças portuguesas ou aos povos de ultramar, as cartinhas bilingües como a que anteriormente mencionamos tinham, além dos objetivos catequéticos evidentes e comuns a todas as obras de tal gênero, três outros objetivos precípuos:

1- Ensinar o alfabeto latino aos povos nativos, falantes de tamul, habilitando-os a ler textos catequéticos ou religiosos nessa língua.

2 - Ensinar português aos falantes de tamul. Com efeito, a expansão do Império Português exigia a expansão da língua portuguesa, ainda que isso se desse numa base bilingüe.

3 - Ensinar tamul aos portugueses. O capitalismo mercantil de um lado e o trabalho missionário de outro exigiam 
que se penetrasse nos sistemas lingüísticos dos povos de ultramar, justamente porque, nos primeiros séculos, as línguas desses seriam mais faladas que as línguas européias. Os dois primeiros séculos de colonização da América, da Ásia e da África conheceram o bilingüismo como elemento definidor da própria cultura colonial. É nesse sentido que se insere a alfabetização dos povos exóticos: deveriam saber a língua do europeu, mas poderiam também falar e ler em sua própria língua (e esta era, com efeito mais falada que aquela). No prólogo de sua Cartilla y Doctrina Christiana... en la lengua Chuchona, o Frei Roldán diz (apud Viñaza,op.cit., p.38):

\footnotetext{
"Y assi acordé de hacer un librito, el qual sirva de Cartilla y doctrina y dialogo. La cartilla sera para enseñar a leer: y la doctrina para doctrinar y enseñar la Doctrina cristiana... Y el Dialogo sirvira de ciertas preguntas, tocantes a la Doctrina Christiana que la declaran. Pongo al principio de la Cartilla el Calendario de los Sanctos, para que sepan los naturales, las fiestas que son de guardar para ellos... Estas dos cosas, Doctrina y Dialogo, van en las dos lenguas."
}

O passo supramencionado é claro: traduziam-se textos para que os naturais da terra lessem na lingua indigena. Assim, ao contrário do que muitos supõem, nem toda a literatura catequética produzida por europeus destinava-se, tão somente, a ser ouvida pelos povos exóticos e lida pelos próprios europeus. Uma vez aprendendo a ler, textos ser-lhes-iam destinados, sem que sua leitura fosse mediada pelos missionários.

Quanto à existência de cartilhas em línguas africanas, informa-nos Pinto (1948, p. 327), que as houve, por exemplo, no Congo:

"Em 1624, o Padre Mateus Cardoso que ali dirigia a missão dos jesuitas, traduziu a célebre cartilha de Marcos Jorge para a língua do Congo, dedicando-a ao muito poderoso e católico Rei do Congo D. Pedro Afonso, segundo 
deste nome. Nota Inocêncio que a versão é interlinear, trazendo primeiramente o texto em português e, por baixo de cada regra, a tradução correspondente em língua conguesa."

\subsection{O DOMÍNIO DA TRÍADE DICIONÁRIO-GRAMÁTICA- CATECISMO NAS SOCIEDADES ÁGRAFAS}

A catequese, com efeito, era o corolário do trabalho de dicionarização e gramaticalização. Assim, na tríade vocabulário, gramática e literatura catequética esgotavam-se as exigências de produção de textos que se punham diante das ordens religiosas e de seus devotados missionários. Tal literatura catequética, na América Latina incluía:

- O Catecismo Romano propriamente dito (contendo a doutrina cristã) vertido para as línguas indígenas

- Sermões e homilias

- Orações seguidas às cartilhas, para o ensino da religião para as crianças, concomitantemente com o ensino da língua indígena (p. ex., a Cartilla para los niños en lengua Tarasca, pelo Frei Maturino Gilberti, México, 1559)

- Confessionários

- Santorais

- Exercícios espirituais quotidianos

- Salmodia cristã e cantos religiosos

- Tradução das Epístolas e dos Evangelhos

- Tradução de bulas papais para as línguas indígenas

- Biografia de índios piedosos (P. ex., La Vida y Muerte de tres niños de Tlaxcalla, que murieron por la confesion de la $\mathrm{Fe}$, traduzida para o nahuatl por Fray Iuan Baptista, México, 1601)

- Manuais de párocos (Missais) 
- Biografias de santos

- Obras sobre a vida de Jesus

- Manual dos sacramentos

- Autos e poemas religiosos

O catálogo de Viñaza (1892, p. 96) consigna, ademais, uma obra de cunho profano em língua indigena: trata-se de uma tradução para o nahuatl, língua nacional do México de hoje, de três comédias de Lope de Vega, feita por Bartolomé Alba, em 1641. Não consta, porém, que tenha sido publicada jamais.

Grandes eram os desafios para os missionários da América, que dotariam demiurgicamente as linguas americanas de uma escrita, elas que tinham somente uma tradição oral. Das dificuldades que aí topavam os que se arrostavam com tão árduo empreendimento dá-nos conta o passo do famoso "Sermão do Espírito Santo" do Padre Vieira (1959):

"Pois se a Santo Agostinho, sendo Santo Agostinho, se à águia dos entendimentos humanos se lhe fez tão dificultoso aprender a língua grega, que está tão vulgarizada entre os latinos e tão facilitada com mestres, com livros, com artes, com vocabulários e com todos os outros instrumentos de aprender, que serão as línguas bárbaras e barbaríssimas de umas gentes onde nunca houve quem soubesse ler nem escrever? Que será aprender o nheengaíba, o juruna, o tapajó, o tremembé, o mamaianá, que só os nomes parece que fazem horror?

As letras dos Chinas e dos Japões muita dificuldade têm porque são letras hieroglificas, como a dos Egípcios; mas, enfim, é aprender línguas de gente política e estudar por letra e por papel. Mas haver de arrostar com uma língua bruta e de brutos, sem livro, sem mestre, sem guia e no meio daquela escuridade e dissonância haver de cavar os primeiros alicerces e descobrir os primeiros rudimentos dela; distinguir o nome, o verbo, o advérbio, a proposição, o número, o caso, o tempo, o modo e modos nunca 
vistos nem imaginados, como o de homens enfim tão diferentes dos outros nas línguas como nos costumes não há dúvida que é empresa muito árdua a qualquer entendimento e muito mais árdua à vontade que não estiver muito sacrificada e muito unida com Deus." (vol. II, p. 415416)

\section{3.- A traduÇão De teXTos NAS SOCIEDADES LETRADAS DE ALÉM-MAR: O EXEMPLO DO MISSIONÁRIO MATTTEO RICCI}

Nem sempre, contudo, se estava diante de linguas de tradição puramente oral. No século XVI os europeus defrontaram-se também com sociedades complexas que já conheciam a escrita e que já possuiam literatura escrita mais que milenar: foi o caso dos chineses, dos japoneses e dos indianos, que possuíam, inclusive, livros religiosos tão antigos ou mais antigos ainda que a Bíblia, como é o caso do Rg Veda e do Tao Te King. Nesse caso, as exigências do estudo lingüístico por parte dos missionários transcendia a mera produção de textos catequéticos. Bem ilustrativo dessa situação deparada pelos missionários na Ásia foi o trabalho do jesuita Matteo Ricci, na China, que chegou a Macau em 1582. Ricci traduziu textos em chinês e de natureza não catequética, com o fito explícito de chamar a atenção da China para sua cultura e, ao interessar os chineses em sua cultura, buscava levá-los a se interessarem pelo seu Deus. Ao enfrentar o desafio de aprender o chinês, afirmava Ricci em carta a um amigo:

"Posso assegurar-lhe que é algo completamente diferente do grego ou do alemão. Na língua falada, há tanta ambigüidade que existem muitas palavras que podem significar mais de mil coisas e, muitas vezes, a única diferença entre uma palavra e outra é a forma como você dá a entonação alta ou baixa, em quatro diferentes tons... Todas as letras escritas diferem umas das outras. Quanto a essas letras escritas, você não acreditaria sem vê-las e usá- 
las, como fiz. Eles têm tantas letras quantas são as palavras e as coisas, de modo que existem mais de setenta mil delas, cada uma totalmente diferente e complexa."

(apud Spence, 1986, p. 152)

Para obstar a toda essa dificuldade (também sentida pelos próprios chineses) de aprender a escrever a língua chinesa, Matteo Ricci criou um método mnemônico que deixou a aristocracia chinesa estupefacta. Havia quem dissesse que ele podia lembrar qualquer livro que lera de passagem apenas um vez (Opere Storiche, p. 235-236, apud Spence, op. cit., p. 155).

Desse modo, valendo-se de seu prestígio junto aos letrados da China, Ricci escreveu em Chinês Dez Discursos de um Homem Paradoxal (1608), que continha uma transcrição da vida do fabulista grego Esopo por Planudes e paráfrases do filósofo Epicteto, Sobre a Amizade (1559), onde ele citou dezenas de autores clássicos, Vinte e Cinco Sentenças (1605), seleção de pensamentos de Epicteto. Ricci, por outro lado, traduziu para o chinês os Elementos de Geometria de Euclides e executou trabalhos em Óptica, Astronomia, Geografia, levantamentos topográficos, Horologia. Ricci buscava envolver os chineses em suas realizações científicas para que esses se tornassem mais receptivos à fé cristã. Conforme disse a Clavius, seu antigo mestre, em 1597 (apud Spence, op. cit., p. 165), ele "entalhou mensagens em chinês nas bases de seus quadrantes desmontáveis, apontando a fragilidade da conduta humana se não viesse acompanhada de alguma compreensão da graça de Deus e advertindo aos que olhavam o tempo passar pela face do quadrante solar que não poderiam recapturar o passado nem antever o futuro, mas deviam fazer o bem no presente, enquanto tinham oportunidade para tal".

No campo catequético stricto sensu, Matteo Ricci imprimiu em chinês o Verdadeiro Significado do Senhor do Céu (Tianzhu shiyi), um sumário da doutrina cristã em que dialogam um chinês e um erudito cristão e onde Ricci apresenta célebres argumentos éticos da tradição clássica greco-roma- 
na, entre os quais o conhecido "Mito da Caverna", de A República de Platão.

Contudo, se em certas regiões as necessidades de produção de textos não se resumiam à tríade "vocabulário-gramática-catecismo", espraiando-se para o campo da Ética, das ciências e da Apologética, isso foi mais uma exceção que uma regra. Na América e na África foi exatamente aquela triade que predominou, com raros desvios para campos conexos, como é o caso da poesia tupi de Anchieta e também de seu teatro naquela língua.

\subsection{A INTERTEXTUALIDADE NAS GRAMÁTICAS DAS LÍNGUAS EXÓTICAS: O SUPLETIVISMO COMO MEIO DE ENQUADRAMENTO NO MODELO LATINO}

A elaboração das gramáticas das línguas exóticas segundo os quadros da gramática latina clássica não se daria, amiúde, sem a percepção do fato de que se estava diante de sistemas lingüísticos diferentes. Assumindo uma perspectiva comparativista, muitos gramáticos apontaram o que se afastava do modelo latino no sistema lingüístico que analisavam e descreviam. Partindo de um modelo tomado como ideal, como paradigmático, buscava-se, muitas vezes, "suprir" categorias latinas sem exatos correspondentes nas linguas exóticas por formas semanticamente próximas, mas sem nenhuma correlação estrutural com as categorias que se buscava suprir. A nosso ver, no supletivismo reside o cerne do conceito de latinização. Latiniza-se sempre que se "supre" o que o modelo tutelar latino posssui para que sua validade universal não se rompa, sempre que conteúdos tomem o lugar das formas e busquem equivaler a estas.

Uma forma supletivista é, com efeito, aquela que supre as faltas de um paradigma. Desse modo, podemos dizer que o feminino de aluno é aluna; mas cavalo não faz "cavala", que 
não existe, mas sim égua. Estamos, pois, suprindo paradigma da flexão de gênero com um termo que só semanticamente é adequado (a égua, com efeito, é o feminino do cavalo) mas não formalmente, pois são dois termos diferentes.

Ao dizerem as gramáticas tradicionais do português que mulher é o feminino de homem, estão a suprir um paradigma de flexão, que em nossa língua é uma só (com poucos alomorfes): o acréscimo do sufixo - $a$ para o feminino, com a eliminação da vogal temática, se ela existir, no singular:

$$
\begin{aligned}
& \text { menin }(0)+a=\text { menina } \\
& \text { pintor }+\mathrm{a}=\text { pintora } \\
& \text { homem } "=\text { mulher (forma supletivista) }
\end{aligned}
$$

Assim, através do supletivismo das formas, grande parte das gramáticas das línguas exóticas foi elaborada nos séculos XVI e XVII. A tão mencionada "latinização" reside fundamentalmente nesse processo de forçar equivalências e preencher os vácuos dos paradigmas latinos com formas próprias das línguas exóticas.

Os seguintes textos exemplificam o que expusemos anteriormente:

Pedro de Alcalá, Arte para ligerame)te saber la lengua araviga, 1.505

"Capitulo IX - De la materia de los pronombres y de su supleción

Dicho de los nombres y de su declinacion, avemos agora de dezir de los pronombres y de la manera en que son suplidos de su declinacion...

(...) genitivo sui no tiene en aravigo pronombre correspondiente, mas suplese con esta letra $\mathrm{V}$ en el singular."

Capitulo $X-$ De los pronombres possessivos

Non tenemos en el aravia los siete pronombres possessivos que son: Noster, Nostras, Tuus, Vester, Vestras y Suus, Sua, Suum. Mas suplese con algunas dicciones o silabas que son llamadas damires... Meus, mea, meum, se 
suple con una i añadida a qlquiera nombre aun que el tal nombre acabe en i. Exemplo: Mi cavallo, faraci)"

O texto acima ilustra bem os conceitos de correspondência e de supletivismo: "correspondente" é uma forma que está em relação biunívoca com outra da língua latina (assim como mon do francês o está para meu do português: traduzimos sempre um pelo outro). Já uma forma "supletiva" tem somente com dado termo latino uma correspondência semântica, mas não formal (como o $i$ do árabe, que se acrescenta a qualquer nome e significa meu ou minha, meus ou minhas). $\mathrm{Xe}$ em tupi supre os possesssivos meu, minha, meus, minhas. Significa também eu. Não está, dessarte, em correspondência biunívoca com um termo português, mas traduz, supre várias formas gramaticais.

Pe. Diego de Torres Rubio, S.J., Arte de la lengua Aymara, 1616

(...) No ay mas que una conjugacion, cuya terminacion es: tha y por ella van todos los verbos. Tiene todos los modos aunque no todos los tiempos; pero puedese suplir por otros. (fol. 6a)

(...) En esta lengua no hay este verbo possum, pero suplese de dos maneras, o con uno destos dos verbos yatisha, huaquistha, en las terceras personas, que a este proposito quiere decir, tener effecto o ponerse en execucion alguna cosa." (fol. 40)

Pe. Diego Gonzales de Holguin, Gramatica y Arte Nueva de la Lengua General de todo el Peru, llamada lengua Qquichua o lengua del Inca, 1607

"Añadida y cumplida en todo lo que le falta de tiempos y de la grammatica y recogida en forma de Arte lo mas necessario en los dos primeiros libros." (Frontispício)

O frontispício da gramática de Holguin é bem elucidativo. A zona das correspondências possiveis ou do supletivismo é añadida e cumplida com o que falta à gramática quêchua para 
equivaler ao modelo universal latino. O passo seguinte é muito esclarecedor a tal respeito:

"El mas famoso ablativo comum es el ablativo absoluto latino y aunque aca no ay propria forma determinada para el, mas hallamos que la suplen por el subjuntivo muy cumplidamente y assi damos aqui por ablativo absoluto al subjuntivo en todas sus personas y mas en la tercera como Deo volente, Dios munaptintac, Governando Philipo rey, Philipo tocricuptintac, queriendo tu, cam munaptiyquitac.

(...)Yten los nõbres q) en Latin rijen ablativo de qualidades como flavus capillis, niger oculis los ay aca propriamente imitados, como Paco chue cha, el de los cabellos rojos. Yana ñavi, el de ojos negros.” (fol. 95)

\section{Pe. Pedro Marban, S.J., Arte de la lengua moxa,} 1.702

"No ay en esta lengua diccion simple que tenga todos los modos y tiempos que el sum es fui en la Latina; sino que en algunos tiempos se suple y en otros se haze con varias particulas que se iran explicando." (p. 90)

Arte y Vocabulario de la lengua morocosi (Anônimo), 1.699 (apud Viñaza, op. cit., p. 123-124)

"No hay en esta lengua rigurosa declinacion, porque no se le halla particular ninguna que distinga los casos unos de los otros. Suplese en lo más con los pronombres possessivos. Y el dativo para, se suple con el futuro imperfecto del verbo substantivo."

- "No ay en esta Lengua verbo substantivo que tenga todos los modos y tiempos que el verbo sum es fui en Latin, sino que en algunos tiempos se suple y en otros se haze con varias particulas."

\section{Pe. Pedro Dias, Arte da Lingua d'Angola, 1698}

"Os pronomes primitivos suprem a interjeição Ó, v.g., Eye mucuâhenda nguicuatece. Ó vós compassivo, favorecei-me. O exemplo está em eye, que serve de interjeição.” (p. 47) 
Pedro Dias apresenta, no passo seguinte, a forma correspondente, no quimbundo, à partícula ut (para que) do latim e as formas supletivistas:

"Para se explicar nesta lingua a partícula ut, "para que", usa-se do advérbio Da, que significa "para que",v.g., Nzambi ü abanga atu nda aye coülo. Deos fez os homens para q vão ao ceo. O exemplo está em nda, antes do verbo aye.

Há outros modos de explicar o mesmo sentido, os quais ponho aqui para maior notícia.

- Primeiro modo: usar o gerundio em di.

- Segundo por relativo...

- Terceiro he pór o segundo verbo no imperativo, como accusativo do primeiro.

- Quarto modo he pór o segundo verbo no imperativo v.g. Ngacuriondo, nguiloloque. Peçovos, perdoayme. O exemplo está no imperativo, nguiloloque." (p. 49)

Pe. João Rodrigues, Arte Breve da Lingua Iapoa, 1.620

Na obra gramatical de João Rodrigues, modelada imagine et similitudine da de Manuel Álvares, está, amiúde, explícito o supletivismo das formas:

"Os participios presentes \& futuro se suprem com as particulas Mono, Hito, Ua, Uo \& c. Que sam propriamente oraçoens de relativo, como se disse nas conjugaçoens." (fol. 58)

(...)Carece esta lingoa dos provocabulos relativos que respondem a Qui, Quae, Quod... \& quando a oraçam he relativa supren o relativo tacitamente no modo de fallar $\&$ collocaçam do antecedente em respeito do verbo de que se rege."

(fol. 17 b) (grifos nossos)

\section{ConClusões}

Poucos séculos da história humana assistiram a tantas transformações nos diversos campos da atividade hu- 
mana quanto os séculos XVI e XVII. A expansão dos limites geográficos do mundo conhecido, a definição do mapa do orbe terrestre levou os europeus a se depararem com uma vasta gama de culturas e de línguas de cuja existência nem sequer se suspeitava antes. Assistiu-se, assim, à erecção de uma nova Babel, pois foi nesse momento histórico que os homens de todo o mundo souberam da existência uns dos outros.

A expansão colonial européia pelo mundo, seguida pela expansão do Cristianismo pelos novos continentes descobertos pelos europeus levavam à necessidade premente de se produzirem textos que seriam instrumentos dessa expansão. Em primeiro lugar, conhecer as línguas exóticas interessava a todos os que se envolviam na empresa colonial. Os dicionários e as gramáticas foram os instrumentos para isso. Em segundo lugar, a conversão dos povos exigia textos catequéticos. Neles vislumbram-se diversos deslocamentos semânticos e a necessidade de se penetrar na esfera simbólica dos povos dominados, ao mesmo tempo em que se buscava inserir sua cultura nos modelos produzidos na Europa, que vivia uns de seus momentos históricos mais ricos, quais sejam, o do Renascimento e, mais tarde, o do Racionalismo.

Apesar de todas as conseqüências nefastas que o processo de tradução de textos pelos europeus teve para as sociedades coloniais, é certo que isso dotou suas línguas de uma literatura e permitiu documentar, desde os primeiros séculos da colonização, as línguas dos continentes de alémmar. Embora os resultados da evangelização tenham sido fraquíssimos na Ásia e na África, naqueles dois séculos (ao contrário da América, que se cristianizou quase inteiramente), os missionários deram importante contribuição para o conhecimento daquelas linguas e hoje os únicos documentos de que se dispõe para se conhecerem muitas dessas línguas são precisamente os que eles nos legaram. 


\section{BibLIOGRAFIA}

ALCALÁ, P. Arte para ligerame)te saber la lengua araviga. Granada: Juan Varella de Salamanca, 1505.

ARAÚJO, A. Catecismo na Língua Brasílica (1618). Rio de Janeiro: PUC, 1952.

BUESCU, M. L. C. O Estudo das Linguas Exóticas no Século XVI. Lisboa: Instituto de Cultura e Língua Portuguesa, 1983.

COROMINAS. Diccionario Crítico Etimologico de la Lengua Castellana. Madrid: Editorial Gredos, 1954.

DIAS, P. Arte da Língua d'Angola. Lisboa: Officina de Miguel Deslandes, 1697.

FONSECA, Q. "O conhecimento das línguas africanas e orientais auxiliando a expansão do Império Português". Memórias da Academia das Ciências de Lisboa, tomo III. Lisboa, 1940, p. 157-169.

HOLGUIN, D. G. Gramática y Arte Nueva de la Lengua General de todo el Peru, llamada lengua Qquichua o lengua del Inca. Lima: Francisco del Canto Impressor, 1607.

KUKENHEIM, L. Contributions à l'Histoire de la Grammaire Italiènne, Espagnole et Française à l'Époque de la Renaissance. Amsterdam: Noord-Hollandsche Uitgevers-Maatschapiij, 1932.

LITTRÉ, E. Dictionnaire de la Langue Française. Paris: Librairie Hachette, s.d.

MARBAN, P. Arte de la lengua moxa, con su vocabulario y cathecismo. Lima, 1702 (?).

MORAIS SILVA, A. Grande Dicionário da Língua Portuguesa. Lisboa: Editorial Confluência, s.d.

NEBRIJA, E. A. Gramática de la Lengua Castellana (1492). (Introdução de A. Quilis). Madrid: Editora Nacional, 1980.

PINTO, A. C. Da Famosa Arte da Imprimissão. Lisboa, 1948.

RODRIGUES, J. Arte Breve da Lingoa Iapoa. Macau, 1620.

RUBIO, D. T. Arte de la lengua aymara. Lima: Francisco del Canto, 1616.

SPENCE, J. D. O palácio da memória de Matteo Ricci. São Paulo: Companhia das Letras, 1986.

VIEIRA, A. Sermões. Porto: Lello e Irmão Editores, 1959.

VIÑAZA,Conde de. Bibliografia Española de Lenguas Indigenas de America. Madrid: Est. Tip. Sucesores de Rivadeneyra, 1892. 
ABSTRACT: The translation of texts into american, african and asiatic languages, in the XVIth and XVIIth centuries, made by europeans who were beginning to stablish colonies overseas, had the main purpose of converting other peoples to Christianity. Those texts were directed both to local populations and to missionaries and they displayed a larger variety among literate societies. Regarding grammars, one realizes the strong intertextuality with reference to the latin grammar, on the model of which all other grammars should be written. This paper displays the kinds of texts which were translated into the so said "exotic languages" in those two centuries.

Keywords: exotic languages, translation, missionaries. 